\title{
Physical Educators' Attitude Toward Teaching Students With Special Educational Needs
}

\begin{abstract}
Sibel Nalbant ${ }^{1}$
${ }^{1}$ Istanbul Gedik University, tasralisibel@gmail.com

Received: 19.09.2018

doi: 10.30655/besad.2018.9

Accepted: 26.09.2018

url: https://doi.org/10.30655/besad.2018.9

Abstract

The purpose of this research was to evaluating the national and international literature on the attitudes of physical education teachers towards students with special educational needs. As a result, physical education teacher candidates, although very enthusiastic about teaching individuals with special needs, do not feel safe; because the education they receive during university education remains in theory and away from the real environment. This education, which is rather theoretical rather than practical, causes the attitudes of teachers to be complicated. Based on this result, it can be said that adapted physical education, sports and special education courses do not contribute to the development of positive attitude at the desired level. These results require that the physical education teacher education program be reaudited to ensure positive attitude development towards students with special educational needs.
\end{abstract}

Keywords: Physical educators, attitude, students with special educational needs

\section{Beden Eğitimi Öğretmenlerinin Özel Gereksinimli Öğrencilere Yönelik Tutumları}

\section{$\ddot{\mathbf{O} z}$}

Beden eğitimi ögretmenlerinin özel gereksinimli öğrencilere yönelik tutumları konusunda ulusal ve uluslararası alandaki alan yazını değerlendirmek amacı ile yapılan bu çalışmada, beden eğitimi öğretmen adaylarının, üniversite eğitimi sürecinde aldıkları ĕgitimin, uygulamadan çok teoriye dayalı olmasından ve mesleki hazırlık sürecinde özel gereksinimli öğrenciyi ögretme deneyimlerinin olmamasından dolayı öğretme konusunda istekli olmalarına rağmen mesleki başarısızlık kaygısı ve öğretmeye hazır olmadıklarını hissettikleri için tutumlarının kararsız ve karmaşık olduğu sonucuna ulaşılmıştır. Buradan yola çıkarak beden eğitimi öğretmenliğine hazırlanma sürecinde aldıkları uyarlanmış beden eğitimi ve

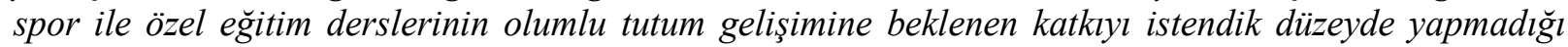
söylenebilir. Bu sonuçlar beden eğitimi ögretmeni yetiştirme programının özel gereksinimli bireylere yönelik olumlu tutum gelişimini sağlama açısından yeniden gözden geçirilmesini gerektirmektedir.

Anahtar kelimeler: Beden eğitimi öğretmeni, tutum, özel gereksinimli birey. 


\section{Giriş}

Bireysel farklılık insan gelişiminin temel ilkelerindendir. Bu farklılıklar kimi çocuğun normal eğitim olanaklarından yararlanmasına engel teşkil etmez iken kimi çocuklarda bazı özel düzenlemelere gidilmesini gerektirebilir. Bu noktada özel eğitim devreye girmektedir. Özel eğitimden yararlanan kişiler özel gereksinimli olarak adlandırılır. Özel gereksinimli, tanılanmış bir gelişimsel yetersizliği bulunan, gelişimsel geriliği olan ya da gelişimsel gerilik için risk altında olan çocuklardır (Lerner ve ark, 2003).

Özel eğitim genel eğitimin ayrılmaz bir parçasıdır. Günümüzde özel eğitim uygulamasına yönelik güncel akım, bu bireyleri akranlarından ayırmadan özel eğitim gereksinimlerinin, normal okul ve sınıf ortamlarında karşılanması yönündedir. Özel gereksinimli öğrencilerin akranlarıyla birlikte aynı okullarda ve aynı sınıflarda eğitim alması düşüncesi, 1960'lı yıllarda insan hakları ile genel ve özel eğitim alanlarında yaşanan gelişmelere paralel olarak ortaya çıkmıştır. Uluslararası kuruluşlar giderek artan biçimde bu konuyla ilgilenmeye, tüm çocukların farklılıklarını göz önünde bulunduran ve gereksinimlerini karşılayacak genel eğitim okulları oluşturulmasını talep ederek devletlerin eğitim politikalarını etkilemeye başlamışlardır. 1994 yılında Salamanca, İspanya'da 92 devlet ve 25 uluslararası kuruluştan 300'ü aşkın kişinin katıldığı Özel Eğitim Dünya Konferansı gerçekleştirilmiştir. Konferansla, herkes için eğitim hedefi doğrultusunda bütünleştirme yaklaşımının geliştirilmesi ve okulların özellikle özel gereksinimli çocuklar olmak üzere tüm çocuklara hizmet vermesini sağlamada gerekli siyasal adımların atılması amaçlanmıştır. Salamanca Bildirgesi, özel gereksinimli çocukların genel eğitim sistemi içinde eğitim almaları için çağrıda bulunan ilk uluslararası belgedir. (UNESCO, 1994)

2006 yılında Birleşmiş Milletler Genel Kurulu'nda kabul edilen Birleşmiş Milletler (BM) Engelli Bireylerin Hakları Sözleşme (EHS)'nin 24. maddesiyle bütünleştirme yoluyla eğitim alma hakkı uluslararası hukukta güvence altına alınmıştır. BM EHS 30. Maddede yer alan "Taraf Devletler engellilerin diğer bireylerle eşit koşullar altında kültürel yaşama, dinlenme, boş zaman aktiviteleri ve spor faaliyetlerine katılım hakkını tanır ve engellilerin bu haklardan yararlanması için gerekli tüm tedbirleri alır” ifadesi ile de beden eğitimi hizmetlerinin sunulması açısından önemlidir. 30. Maddenin 5. fikrasında belirtilen haklar;

(a) Engellilerin her seviyedeki genel spor etkinliklerine mümkün olduğunca tam katılımını cesaretlendirmek ve artırmak; 
(b) Engellilerin, özel spor ve eğlence etkinliklerini örgütleme, geliştirme ve bu etkinliklere katılma imkânına sahip olmasını temin etmek ve bu nedenle, diğer bireylerle eşit koşullar altında onlara uygun bilgi ve eğitimin verilmesini ve kaynakların sunulmasını sağlamak;

(c) Engellilerin spor, eğlence yerleri ile turistik alanlara erişimini sağlamak;

(d) Engelli çocukların, okullardaki etkinlikler dâhil olmak üzere, oyun, eğlence, boş zaman aktiviteleri ve spor etkinliklerine eşit şekilde katılabilmelerini sağlamak;

(e) Eğlence, turistik, boş zaman aktiviteleri ve spor etkinliklerini organize edenlerin sunduğu hizmetlere engellilerin erişebilmesini sağlamak.

Özel gereksinimli çocukların eğitim, toplumla bütünleşme ve spor hakları için sadece engelli bireylere yönelik uluslararası sözleşmeleri referans göstermemiz eksik kalır. Özel gereksinimi olan çocuklar da nihai olarak "çocuk” tur. Çocuk olarak da hakları vardır. Birleşmiş Milletler (BM) Çocuk Hakları Sözleşmesi (ÇHS)'nin 31. Maddesi “Çocukların boş zamanlarını değerlendirebilmeleri, kendilerini geliştirebilmeleri için oyun bahçeleri, çocuk kulüpleri, kütüphaneler, spor ve kültür merkezleri açılmalıdır. Her çocuğun bu tür etkinliklere katılma hakkı vardır" der. Madde 32 ise "çocukların okula gitme, oyun oynama” hakkına vurgu yapar. BM EHS ve BM ÇHS devletlerin imza koyduğu ve onayladıktan sonra yasal olarak uymaları gereken uluslararası antlaşmalardır. Tüm bu antlaşmalar Türkiye'deki eğitim sistemine de kademeli olarak yansımış 1983 yılında yürürlüğe giren Özel Eğitime Muhtaç Çocuklar Kanunu ile başlayan kaynaştırma uygulamaları, 1997 yılında yürürlüğe giren 573 sayılı Kanun Hükmünde Kararname ve 2000 yılında yürürlüğe giren Milli Eğitim Bakanlığı Özel Eğitim Hizmetleri Yönetmeliği ile yaygınlaşmıştır.

Yapılan bu düzenlemelerle son yıllarda kaynaştırma oranının artmasına rağmen ülkemizde kaynaştırmaya katılan öğrenci sayısı ile ilgili okul dönemlerine ilişkin çarpıcı sonuçlar olduğu görülmektedir. Eğitim Reformu Girişimi, 10. Eğitim İzleme Raporu'na göre 2016- 2017 eğitim öğretim yılında örgün eğitimde kaynaştırmaya katılan öğrenci sayıları incelendiğinde, ilkokul (79.029) ve ortaokul döneminde (105.333) kaynaştırmaya katılım sayısı umut vaadedici olmakla birlikte okul öncesi (3.585) ve ortaöğretim/lisede (33.658) kaynaştırmaya katılım sayısının oldukça düşük olduğu dikkati çekmektedir.

Okul öncesi yılları, kişiliğin oluşumu ve şekillenmesi, temel bilgi, beceri ve alışkanlıkların kazanılması ve geliştirilmesinde ileri yıllara olan etkisi nedeniyle, yaşamın en kritik dönemlerindendir. Çocuğa erken yaşlarda sağlanacak deneyimlerle elde edilecek temel bilgi, beceri ve alışkanlıklar, çocuğun daha sonraki öğrenim yaşamının yanı sıra, sosyal ve duygusal 
yaşamını da bilinçlendirecek güçtedir. $\mathrm{Bu}$ yönü ile düşünüldüğünde okul öncesi dönemde kaynaştırma daha büyük anlam ifade etmektedir. Okul öncesi dönem kaynaştırma oranının arttırılması için gerekli olan önleyici tedbirlerin alınması gerekmektedir. Ortaöğretim/lise dönemi ise kişinin kendini gerçekleştirmesi, üretken bir birey olarak yaşama başarılı katılım sağlaması için en önemli dönemdir. Ancak sayısal veriler, ortaokul ile ortaöğretim/lise arasında özel gereksinimli öğrencilerin okula devamlılığında yüksek oranda düşüş olduğunu göstermektedir. Mesleki ve teknik eğitim liselerine, güzel sanatlar, konservatuar, spor ve sağlık liselerine giriş için yapılan sınav ve yerleştirmelerde özel gereksinimli öğrencilerin durumlarının dikkate alınması ve yönetmeliklerdeki kısıtlılıkların düzenlenmesi ile özel gereksinimli öğrencilerin ortaöğrenimden yararlanma oranının arttırılabileceği düşünülmektedir.

Ülkemizde ve dünyada özel gereksinimli bireylere ve özel eğitime verilen önem giderek artmaktadır. Bunun bir sonucu olarak da özel gereksinimli öğrencilerin, tipik gelişim gösteren öğrencilerle birlikte eğitimin firsat ve imkân eşitliği ilkesine dayalı olarak eğitim faaliyetlerine katılma oranı artış göstermektedir (ERG, 2017). Son yıllarda yapılan yasal düzenlemelerle ülkemizde, kaynaştırma oranı 2002-2003 eğitim-öğretim yılından (ilköğretim ve ortaöğretimde kaynaştırma öğrencisi sayısı 31.049), 2016-2017 yılına kadar (ilköğretim ve ortaöğretimde kaynaştırma öğrencisi sayısı 218.020) yüksek oranda artmıştır.

Kaynaştırmada en önemli rolü üstlenen öğretmenler açısından düşünüldüğünde bu durum, diğer öğretmenler gibi beden eğitimi öğretmenlerine de sınıflarında özel gereksinimli öğrencilere öğretme sorumluluğu ve zorunluluğu getirmiştir. Kaynaştırma sadece özel gereksinimi olan öğrencinin akranları ile aynı ortama yerleştirilmesi anlamına gelmemektedir. Başarılı bir kaynaştırma için okul genelinde bir kaynaştırma politikası oluşturulması; okul personelinin özel gereksinimi olan öğrencilere karşı kabul edici ve destekleyici bir tutum sergilemesi, genel eğitim sınıflarının her öğrencinin gereksinimlerini karşılayacak şekilde öğrenmelerini kolaylaştırıcı biçimde düzenlenmesi, öğrencilerin birlikte öğrenme, oyun, eğitimsel ve sosyal etkinliklere katılma fırsatlarına sahip olmalarının, kaynaştırma sınıflarındaki öğrencilerin özel gereksinimi olan akranları hakkında bilgilendirilmesi ve velilerin tümü ile işbirliği sağlanması gerekmektedir (Sucuoğlu ve Kargın, 2006). Başarılı bir kaynaştırma bu ilkeler ile birlikte, sınıf öğretmeni ve/veya özel gereksinimi olan öğrenciye destek özel eğitim hizmetlerinin sağlanması koşulu ile yürütülmektedir (Sucuoğlu ve Kargın, 2006; Kırcaali, İftar; 1992). Başarılı bir kaynaştırmada anahtar faktör öğretmendir. Genel olarak kaynaştırma sınıflarının başarı ya da başarısızlığının temel nedeninin öğretmen tutumları olduğu belirtilmektedir (Dart, 2007; Kuyini ve Mangope, 2011; Mittler, 2003). Öğretmenin rolü kaynaştırmanın kolaylaştırıcısı ve eğitim çevresinin 
yöneticisi olması açısından büyük önem taşımaktadır (Morley ve ark, 2005; Block ve Obrusnikova, 2007).

\section{Tartışma}

Ulusal ve uluslararası alanda özel gereksinimli öğrenciyi öğretmeye yönelik tutumun incelendiği mevcut araştırmalar gerek beden eğitimi öğretmeninin gerekse öğretmen adaylarının, tutumlarının olumsuz ile kararsız tutum arasında konumlandığını ancak üniversite yıllarında özel gereksinimlilerle ilgili lisans dersleri alanların tutumlarının almayanlara göre olumlu olduğunu ortaya koymuştur (Acak, 2016; Akbuğa ve Gürsel, 2007; Coates ve Vickerman, 2008; Fethi, 2017; Gürsel, 2006; Karaçam ve Koca, 2012; Kırımlığlu, 2017; Morley ve ark, 2005; Özer ve ark, 2006; Özer ve Süngü, 2016; Smith ve Green, 2004; Vickerman ve Coates, 2009; Yaman ve ark, 2018). Ayrıca beden eğitimi öğretmen adaylarının, üniversite eğitimi sürecinde aldıkları eğitimin, uygulamadan çok teoriye dayalı ya da gerçek ortamdan uzak olmasından dolayı, özel gereksinimli öğrenciyi öğretme konusunda çok istekli olmalarına rağmen kendilerini güvende hissetmediklerini ve öğretmeye hazır olmadıklarını bildiren çalışmalar da mevcuttur (Coates ve Vickerman, 2008; Karaçam ve Koca, 2012; Kırımlığlu, 2017; Morley ve ark, 2005; Smith ve Green, 2004; Vickerman ve Coates, 2009). Bu sonuç, beden eğitimi öğretmeni adaylarının özel gereksinimli bireyleri öğretmeye yönelik motivasyonunu olumsuz etkileyerek, tutumlarında kararsızlık özelliği oluşmasına neden olmaktadır.

Beden eğitimi öğretmen ve adaylarının tutumunu etkileyen değişkenlerin incelendiği araştırmalar tutarlı olarak genel beden eğitimi öğretmenlerinin farklı yeteneklerdeki çocuklara öğretmeye yönelik tutumlarının başta mesleki hazırlık ile deneyim ve sırası ile desteklerin kullanımı, uygunluğu, kaynaklar, okul politikaları, zaman, sınıf büyüklüğü, öğrencinin engel tipi ve derecesi değişkenlerinden etkilendiğini ortaya koymaktadır (Ammah ve Hodge, 2005; Hodge ve ark, 2004; LaMaster ve ark, 1998; Lieberman ve ark, 2002; Lienert ve ark, 2001).

Beden eğitimi öğretmeni adaylarının ve beden eğitimi öğretmenlerinin özel gereksinimli öğrencilere öğretmeye yönelik tutumları hakkında uluslararası alan yazında tatmin edici sayıda araştırma olmasında karşın (Block ve Obrusnı'kova', 2007; Coates ve Vickerman, 2008; Doulkeridou ve ark, 2011; Fejgin ve ark, 2005; Folsom-Meek ve Rizzo, 2002; Goodwin, ve Watkinson, 2000; Hardin, 2005; Hodge ve ark, 2004, 2009; Meegan ve MacPhail, 2006; Morley ve ark, 2005; Smith ve Green, 2004; Smith, 2004; Standal ve Moe, 2013; Stewart, 1990; Vickerman ve Coates, 2009; Westwood ve Graham, 2003), ülkemizde yeterli araştırma bulunmamaktadır (Acak, 2016; Akbuğa ve Gürsel, 2007; Fethi, 2017; Gürsel, 2006; Karaçam ve 
Koca, 2012; Kırımlığlu, 2017; Özer ve ark, 2013; Özer ve Süngü, 2016; Özer ve ark, 2006; Yaman ve ark, 2018).

\section{Sonuç}

Ulusal ve uluslararası alan yazındaki, mevcut araştırmalar doğrultusunda yapılan bu değerlendirmede dikkati çeken en önemli konu beden eğitimi öğretmeni ve adaylarının mesleki hazırlık ve deneyimlerinin tutumu önemli derecede etkilediğidir. Bilindiği üzere güçlü bir akademik hazırlık beden eğitimi öğretmenlerinin yeterlik duygusu ve etkili öğretimlerinde önemli bir faktördür (Beamer ve Kim, 2014; Obrusnikova, 2008; Özer ve ark, 2013; Tripp ve Rizzo, 2006). Beden eğitimi öğretmenlerinin mesleki hazırlık sürecinde aldıkları uygulamalı derslerin, özel gereksinimli bireyleri yakından tanıma olanağı sağlayıcı yönde olması öğretmen adaylarının meslekte karşılaşabilecekleri sorunları erken deneyimlemesini sağlayacaktır. Sorunları ve çözüm yollarını henüz mesleğe başlamadan önce deneyimleyen beden eğitimi öğretmeni adayı, mesleğini sürdürmeye başladığında problemin çözümü için yararlanacağ 1 yöntemi belirlemede deneyim sahibi olacağı için mesleki başarısı da olumlu yönde etkilenecektir. Böylece olumsuz tutuma neden olan mesleki deneyim sorunu ortadan kalkacak ve özel gereksinimli öğrenciyi öğretme motivasyonu artacaktır. $\mathrm{Bu}$ nedenle beden eğitimi öğretmenlerinin mesleki hazırlıklarını iyi bir şekilde planlamak, uygun deneyimlere sahip olabilecekleri düzenlemeleri yaparak öz yeterlilik duygularını geliştirmek olumlu tutum değişimi için ön koşuldur.

Ulusal alanyazın incelendiğinde mevcut araştırmaların yetersiz olduğu görülmekle birlikte (Acak, 2016; Akbuğa ve Gürsel, 2007; Fethi, 2017; Gürsel, 2006; Karaçam ve Koca, 2012; Kırımlığlu, 2017; Özer ve ark, 2013; Özer ve Süngü, 2016; Özer ve ark, 2006; Yaman ve ark, 2018) beden eğitimi öğretmenlerinin özel gereksinimli çocuklara yönelik tutumları konusunun son yıllarda araştırmalarda daha sık yer alması, sevindirici bir gelişmedir. Bilimsel veri toplama süreçlerine dayanan araştırmalardan elde edilen bulguların alana aktarılmasının, beden eğitiminde kaynaştırmanın etkililik ve verimliliği açısından hayati öneme sahip olduğu düşünülmektedir. Bu nedenle özel gereksinimli çocukların beden eğitimi dersindeki kaynaştırma uygulamalarından beklenen yararları sağlayabilmeleri ve en üst düzeyde kazanım elde edebilmeleri için kaynaştırmanın temel faktörü olan beden eğitimi öğretmenlerinin tutumlarının kanıta dayalı uygulamalı bilimsel çalışmalarla ortaya konması önemlidir. Bu konuda nitelikli öğretimsel uygulamaları sınayan, mevcut durumun geliştirilmesini amaçlayan, kaynaştırmayı "yerleştirme" kavramından öte bütünleşik ortamda ele alan araştırmalar yapılmasının beden eğitiminde kaynaştırmanın etkililiğini ve verimliliğini arttıracağı düşünülmektedir. 


\section{Öneriler;}

- Beden eğitimi öğretmeni yetiştirme programının yeniden gözden geçirilmesi ve seçmeli dersler arasında özel eğitim ve engellilerde beden eğitimi alanında derslere yer verilmesi (Özer ve ark, 2006; Özer ve Süngü, 2016; Özer ve ark, 2013; Gürsel, 2006; Yaman ve ark, 2018).

- Öğretmen adaylarının okul içi ve dışı gönüllü aktivitelere yönlendirilmesi (Block ve Obrusnı'kova', 2007; Özer ve Süngü, 2016).

- Engelliler için beden eğitimi ve spor dersinde öğretmen adaylarına özel gereksinimli çocuklarla çalışma deneyimi sağlanması (Acak 2006; Özer ve ark, 2006; Özer ve Süngü, 2016; Özer ve ark, 2013; Akbuğa ve Gürsel, 2007; Gürsel, 2006; Fejgin ve ark, 2005; Folsom-Meek ve Rizzo, 2002; Yaman ve ark, 2018).

- Davranış problemleri, sınıf yönetimi, öğretim becerileri konusunda yeterli bir rehberlik hizmeti verilerek mesleki yeterliliklerinin geliştirilmesi (Doulkeridou ve ark, 2011; Hardin, 2005).

- Kanıta dayalı uygulamalı bilimsel çalışmalarla öğretmen adaylarının kaynaştırmaya yönelik tutumlarının saptanması ve olumlu tutum geliştirmeleri için müdahale programları hazırlanması önerilmektedir (Meegan ve MacPhail, 2006; Morley ve ark, 2005; Akbuğa ve Gürsel, 2007; Fethi, 2017).

\section{Kaynakça}

Acak, M., Karakaya, Y. E., Tan, Ç., \& Coşkuner, Z. (2016). Engellilerde egzersiz ve spor eğitimi bölümü öğrencilerinin engellilere yönelik tutumlarının incelenmesi. Electronic Turkish Studies, 11(19).

Akbuğa, B., \& Gürsel, F. (2007). Bilgilendirme Yoluyla Beden Eğitimi Spor Yüksekokulu öğrencilerinin engelli bireye yönelik değişen tutumları. Spormetre Beden Eğitimi ve Spor Bilimleri Dergisi, 5(1), 5-8.

Ammah, J., \& S. Hodge. (2005). Secondary physical education teachers' beliefs and practices in teaching students with severe disabilities: A descriptive analysis. The High School Journal 89, no. 2: $40-55$

Arslan, Fethi. (2015). Examination of Physical Education Teacher Candidates' Attitudes towards Individuals with Physical Disability by Visual Information, The Anthropologist, 21:1-2, 197-201, DOI: 10.1080/09720073.2015.11891808

Beamer, J. A., \& Yun, J. (2014). Physical educators' beliefs and self-reported behaviors toward including students with autism spectrum disorder. Adapted Physical Activity Quarterly, 31(4), 362-376.

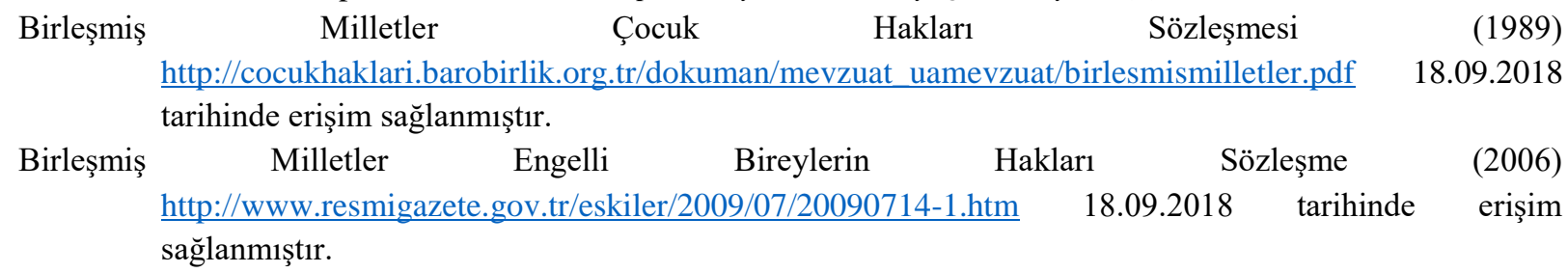

Block, M. E., \& Obrusnikova, I. (2007). Inclusion in physical education: A review of the literature from 1995-2005. Adapted Physical Activity Quarterly, 24(2), 103-124.

Coates, J., \& Vickerman, P. (2008). Let the children have their say: A review of children with special educational needs experiences of Physical Education, Support for Learning, 23(4), 168-175 
Dart, G. (2007). Provision for Learners with Special Educational Needs in Botswana: A Situational Analysis. International Journal of Special Education, 22(2), 56-66.

Doulkeridou, A., Evaggelinou, C., \& Mouratidou, K. (2011). Attitudes of Greek physical education teachers towards inclusion of students with disabilities in physical education classes. International Journal of Special Education 26(1): 1-11

Eğitim Reformu Girişimi 10. Eğitim İzleme Raporu (2016-2017) http://www.egitimreformugirisimi.org/wpcontent/uploads/2017/03/EIR2016 17_12.10.17.web-1.pdf 18.09.2018 tarihinde erişim sağlanmıştır

Fejgin, N., Talmor, R., \& Erlich, I. (2005). Inclusion and burnout in physical education. European Physical Education Review 11(1): 29-50.

Folsom-Meek, SL \& Rizzo, TL. (2002). Validating the physical educators' attitude toward teaching individuals with disabilities III (PEATID III) survey for future professionals. Adapted Physical Activity Quarterly 19(2): $141-154$.

Goodwin, D. L., \& Watkinson, E. J. (2000). Inclusive physical education from the perspective of students with physical disabilities. Adapted Physical Activity Quarterly, 17, 144-160

Gürsel, F. (2006). Engelliler için beden eğitimi ve spor dersinin öğrencilerin engellilere yönelik tutumlarına etkisi. Hacettepe Üniversitesi Ĕ̈itim Fakültesi Dergisi, 31(31).

Hardin, B. (2005). Physical education teachers' reflections on preparation for inclusion. The Physical Educator 62(1): 44-56

Hodge, S., Ammah, JOA., \& Casebolt K. (2004). High school general physical education teachers' behaviors and beliefs associated with inclusion. Sport, Education and Society 9(3): 395-419.

Hodge, S., Ammah, JOA., \& Casebolt K. (2009). A diversity of voices: Physical education teachers' beliefs about inclusion and teaching students with disabilities. International Journal of Disability, Development and Education 56(4): 401-419

Karaçam, M. Ş., \& Koca, C. (2012). Preservice Physical Education Teachers' Awareness of Multiculturalism. Hacettepe Journal of Sport Science 23(3), 89-103.

Kırcaali-İftar, G. (1992). Özel eğitimde kaynaştırma. Ĕgitim ve Bilim, 16(86), 45-50.

Kırımoğlu, H., Dallı, M., Yılmaz, A., \& Say, M. (2017). Öğretmen adaylarının zihinsel engelli bireylerin sportif etkinliklerine yönelik tutum düzeylerinin incelenmesi (Muğla Sttkı Koçman Üniversitesi örneği). Journal of Human Sciences, 14(4), 3116-3125. doi:10.14687/jhs.v14i4.4670

Kuyini, A. B., \& Mangope, B. (2011). Student Teachers' Attitudes and Concerns about Inclusive Education in Ghana and Botswana. International Journal of whole schooling, 7(1), 20-37.

LaMasfer, K., Kinchin, G., Gall, K., \& Siedentop, D. (1998). Inclusion practices of effective elementary specialists. Adapted Physical Activity Quarterly, 15(1), 64-81.

Lerner, J.W., Lowenthal, B., \& Egan, R.W. (2003). Preschool children with special needs: Children at risk and children with disabilities. Boston: Allyn \& Bacon.

Lieberman, L. J., Houston-Wilson, C., \& Kozub, F. M. (2002). Perceived barriers to including students with visual impairments in general physical education. Adapted Physical Activity Quarterly, 19(3), 364-377.

Lienert, C., Sherrill, C., \& Myers, B. (2001). Physical educators' concerns about integrating children with disabilities: A cross-cultural comparison. Adapted Physical Activity Quarterly, 18(1), 1-17.

Meegan, S., Casebolt, K., \& MacPhail, A. (2006). Irish physical educators' attitude toward teaching students with special educational needs. European Physical Education Review 12(1): 75-97.

Mittler, P. (2003). Meeting the needs of people with an intellectual disability: international perspectives' in S Herr, L Gostin, and H Hongju Koh (eds) The Human Rights of Persons with Intellectual Disabilities; Different But Equal. Oxford ve New York: Oxford University Press, p 25, 28.

Morley, D., Bailey, R., Tan, J., \& Cooke, B. (2005). Inclusive physical education: Teachers' views of including pupils with special educational needs and/or disabilities in physical education. European Physical Education Review, 11(1), 84-107.

Obrusnikova, I. (2008). Physical educators' beliefs about teaching children with disabilities. Perceptual and Motor Skills, 106(2), 637-644.

Özer, D., Baran, F., Aktop, A., \& Nalbant, S. (2006). Beden eğitimi öğretmenlerinin zihinsel engelli çocuklara ilişkin tutumlarının incelenmesine yönelik bir ön çalışma. Gazi Beden Eğitimi ve Spor Bilimleri Dergisi, 11(1), 3-8. 
Özer, D., \& Süngü, B. (2016). Beden eğitimi öğretmen adaylarının bakış açısından "engelliler için beden eğitimi ve spor dersi” uygulamaları. Spor Bilimleri Dergisi, 27(1), 1-15.

Özer, D., Nalbant, S., Ağlamış, E., Baran, F., Kaya Samut, P., Aktop, A., \& Hutzler, Y. (2013). Physical education teachers' attitudes towards children with intellectual disability: the impact of time in service, gender, and previous acquaintance. Journal of Intellectual Disability Research, 57(11), 1001-1013. doi: 10.1111/j.1365-2788.2012.01596.x.

Smith, A. (2004). The inclusion of pupils with special educational needs in secondary school physical education. Physical Education \& Sport Pedagogy 9(1): 37-54.

Smith, A., \& Green, K. (2004). Including pupils with special educational needs in secondary school physical education: A sociological analysis of teachers' views. British Journal of Sociology of Education 25(5): 593-607.

Standal, Ø.F., \& Moe, V.F. (2013). Reflective practice in physical education and physical education teacher education: A review of the literature since 1995. Quest 65(2): 220-240.

Stewart, C.C. (1990). Effect of practica types in pre-service adapted physical education curriculum on attitudes toward disabled populations. Journal of Teaching in Physical Education 10(1): 76-83

Sucuoğlu, B., \& Kargın, T. (2006). Illköğretimde kaynaştırma uygulamaları: Yaklaşımlar, yöntemler, teknikler. Ankara: Morpa Yayınc1lı.

Tripp, A., \& Rizzo, T. L. (2006). Disability labels affect physical educators. Adapted Physical Activity Quarterly, 23(3), 310-326.

UNESCO (1994). The Salamanca statement and framework for action on special needs education. http://unesdoc.unesco.org/images/0009/000984/098427eo.pdf adresinden 15.04.2016 tarihinde erişim sağlanmıştır.

Vickerman, P., \& Coates. J.K. (2009). Trainee and recently qualified physical education teachers' perspectives on including children with special educational needs. Physical Education and Sport Pedagogy 14(2): 137153.

Westwood, P. \& Graham, L. (2003). Inclusion of students with special needs: Benefits and obstacles perceived by teachers in New South Wales and South Australia. Australian Journal of Learning Disabilities 8(1): 315 .

Yaman, Ç., Uluışık, V., Hergüner, G., \& Önal, A. (2018). Examining the attitudes of physical education teachers towards special education (the handicapped). Physical Education of Students, 22(4), 207-216. 